\section{SIGNIFICANT TRENDS IN MEDICAL RESEARCH}

\section{Ciba Foundation, Tenth Anniversary} Symposium

Edited by G. E. W. Wolstenholme and $M$. O'ConNor. Pp. 356, illustrated. London: J. \& A. Churchill Ltd. I959. 50s.

An increasing proportion of the books which claim attention from the medical reader takes the form of more or less verbatim reports of the proceedings of symposia. The principle of presenting recent advances in knowledge in this fashion is an admirable one, but symposia reports frequently lose some of their potential value as a result of weaknesses which will be all too familiar to reacuers of this review. It is a pleasure to report that this handsome volume is quite free of these shortcomings.

The tenth anniversary of the Ciba Foundation was marked by the publication (in its fiftieth major volume) of the proceedings of a symposium held in June 1959, when authorities in various departments of medical science reported on advances in their speciality over the preceding 10 years. The topics dealt with range from molecular structure (L. Pauling) to medical education in the U.S.A. (Shannon) and between these limits lies a range of subjects varied enough to justify the title of the symposium. Nearly all of the 15 major contributors succeed in the task of presenting a general account of significant developments in their field; the reported discussions are both extensive and, for once, coherent and the volume was published remarkably soon after the proceedings it reports.

This book can be recommended to all those, whether occupied in the basic sciences or in clinical medicine, whether undergraduate student or senior worker, who require a readable though authoritative account of progress in fields other than their own. And what better way is there of expressing one's appreciation of the work of the Ciba Foundation than by buying this book?

\section{THE PRINCIPLES AND PRACTICE OF MEDICINE}

Edited by Sir Stanley Davidson. Fifth Edition.

Pp. $x i+1,112+$ index and useful data.

Edinburgh and London: E. \& S. Livingstone

Ltd. 1960. 35 s.

Any book that reaches its fifth edition in eight years has little need of commendation from a reviewer. That a textbook of medicine should achieve this enviable position is a remarkable tribute to the quality of the volume, especially in view of the competition in this particular field.

The latest edition incorporates much new material, while the older material has been carefully revised to bring the book up to date. In his preface Sir Stanley Davidson writes: '... it has been possible to achieve the balanced style and com- position which are said to characterize the work of a single author, and at the same time to reflect the diversity and depth of knowledge and experience which can only be contributed by a team of physicians.' To the reader, as he passes from section to section, this uniformity of writing is apparent and one can but echo the words of previous reviewers that this book is another splendid contribution from the Edinburgh School of medicine.

Medical students, general practitioners and consultants will all benefit from reading this volume which offers remarkable value at its price. The indexing is first class.

\section{AMERICAN HANDBOOK OF PSYCHIATRY}

Edited by S. ArIETI. 2 vols. Pp.: vol. I, xix +999 ; vol. 2, ix + ro98. Illustrated. New York: Basic Books Inc. Distributed in Great Britain by The Mayflower Publishing Co. Ltd. 1959. £io.

This is an encyclopaedia of American psychiatry. Its $7 \frac{1}{2}$-in. by Io-in. double-columned pages are filled with contributions by III specialists not merely on clinical psychiatry, but on every aspect from prevention and community care to associated basic sciences and such related fields as religion and mathematics and cybernetics. The complete work is divided into I 5 parts, the volumes not being sold separately, and their presentation is such that it would in any case be comparatively valueless to possess one volume alone.

One of the main purposes of the editorial board was to present every leading school of thought and aim at a balance between the various approaches. This has been successfully achieved and will be welcomed by all who believe in a multi-dimensional approach. The text is of high standard throughout and, in appropriate chapters, particularly where neuro-anatomy or neuro-pathology is the topic, is supplemented by a considerable number of diagrams and high magnification photographs.

Psychopharmacology is, of course, advancing so rapidly that it is impossible for any textbook to be absolutely up to date by the time of publication. There is, therefore, a tendency to generalize about phenothiazine derivatives, and thymoleptics are not even mentioned in the index of 89 pages. It is disappointing, also, to find in a work of this magnitude that there is no reference to the mental picture presented by cases of amphetamine psychosis, which bear such close resemblance to paranoid schizophrenia.

The editor and editorial board are, however, to be congratulated on the final product, which must have involved considerable thought on whether and where any restrictions were to be imposed, but a copy of the complete index in each volume would be a welcome addition. 